\title{
A Dynamic Coefficient of Friction Measurement Device for Shoe/Floor Interface Testing
}

\author{
M. S. Redfern, A. Marcotte, and D. B. Chaffin
}

\begin{abstract}
A dynamic coefficient of friction (COF) measurement device is described for use in recording shoe/floor slip resistance. This device is computercontrolled and allows changes in the shoe/floor interface velocity and vertical force applied during a test. Different sole materials, floors, and contaminants such as water or oil are testable. Repeatability tests of the device were conducted of four velocities $(1,2,5$, and $10 \mathrm{~cm} / \mathrm{s})$, three vertical force levels $(5,10$, and $20 \mathrm{~kg}$ ), and three floor conditions (dry, wet, and oily). These tests showed that the COF measurements were highly repeatable with trial-to-trial standard deviations of from $0.5 \%$ to $4 \%$ of the means under all conditions.
\end{abstract}

Slips and falls are a major cause of injury in the workplace (Ellis, 1985; Strandberg, 1983, Manning \& Shannon, 1981). The U.S. National Safety Council estimates that occupational falls cause 250,000 to 300,000 injuries per year, and result in 1,200 to 1,600 deaths (Pater, 1985). As a result, the prevention of slips and falls is receiving an increasing amount of attention. Recently, this attention has focused on measurement of the "tractive" or slip-resistant properties of flooring and shoes. Current slip-resistance evaluation methods measure the COF of the shoe/floor

Mark S. Redfern, $\mathrm{PhD}$, is an assistant professor, Department of Otolaryngology, University of Pittsburgh Medical School and Department of Industrial Engincering, University of Pittsburg Engineering School. Andrew Marcotte, MSE, is affiliated with the Joyce Institute, Ann Arbor, MI. Don B. Chaffin, $\mathrm{PhD}$, is professor, Department of Industrial and Operations Engineering and Department of Environmental and Industrial Health, University of Michigan.

The authors wish to acknowledge James Foulke and Charles Woolley for their technical assistance in constructing the device. The work was financially supported by Ford Motor Company Body and Assembly Operations Division and a NIOSH postdoctoral fellowship. interface (Redfern \& Bloswick, 1987). These measurements are used by industry, shoe and floor manufacturers, and the legal system as a criterion for rating slip potentials of various flooring conditions.

Although static COF is the most common measurement for rating slip potential, there has been much debate over whether it is the most realistic measure (Perkins, 1983; Andres \& Chafin, 1985; Strandberg, 1983; Redfern \& Adams, 1988). Results from laboratory experiments involving human subjects indicated that most foot slips occur under dynamic foot movement conditions and thus a dynamic COF may be a more appropriate measure of the frictional capabilities of a shoe/floor condition (Strandberg, 1983). Dynamic COFs have been acquired using devices such as the TORTUS, the dynamic sled, and the Brungraber Slipometer (Andres \& Chaffin, 1985). Each of these devices, however, is limited to measuring a constant velocity and a constant applied vertical force.

In the ideal case (perfectly smooth, hard surfaces) this measurement scheme is appropriate. In most shoe/floor COF measure- 
ments, however, the conditions are not ideal. Vertical force and contact velocity will have an effect on the measurements, particularly for rough surfaces and floors with surface contaminants such as water or oil (James, 1983).

The objective of this work was to develop a device and methodology to measure dynamic COF with the ability to vary vertical forces and velocities in order to improve the reliability of dynamic COF measures used in shoe/floor slip testing.

\section{METHOD}

The dynamic COF measurement device consists of a rigid sled, stepper motor, velocity control, and computerized force-recording system (Figure 1). The sled is constructed from rigid aluminum plate. A $10 \mathrm{~cm} \times 11.5$ $\mathrm{cm}$ sample of shoe/sole test material is attached to the bottom of the plate with double-sided carpet tape. Weights are placed on top of the sled plate to create the desired normal forces. Attached to the front side of the sled is a force transducer (load cell) and flexible stainless steel cable rated at $3,880 \mathrm{~N}$ in tension. The other end of the cable is attached to the spindle of the stepper motor. The cable and motor provide the means to pull the sled at various velocities. When the motor is activated the spindle turns, creating tension in the cable, deflecting the load cell, and causing the sled to move. The load cell measures the pulling force required to initiate and sustain the movement. In order to create a pulling force with no vertical component, a pulley is attached to the test platform as shown (Figure 1). The stepper motor (Superior Model M106-178 W) and Compumotor microstepping system/controller are used to pull the sled at the desired velocities. The motor is designed to index in 200 discrete steps per revolution $(1.8 / \mathrm{step})$. The controller is used to remove the "jerking" effect that a discrete 200 -step revolution would have on the sled during a test. By performing a linear interpolation between each of the 200 motor steps, the controller "smooths" the stepping effect to create a near continuous pulling force on the sled. The motor spindle is then capable of indexing in 25,000 steps/revolution. A 2001 Sweepable Function Generator (Global Specialties Model 105-2001) is used with the controller to set the motor speed (rate of stepping) and corresponding velocity of the sled during motion. This is possible because the controller creates a direct relationship between the input frequency and motor rota-

\section{FIGURE 1. A DIAGRAM OF THE DYNAMIC COF MEASUREMENT DEVICE WITH COMPUTER DATA}

ACQUISITION

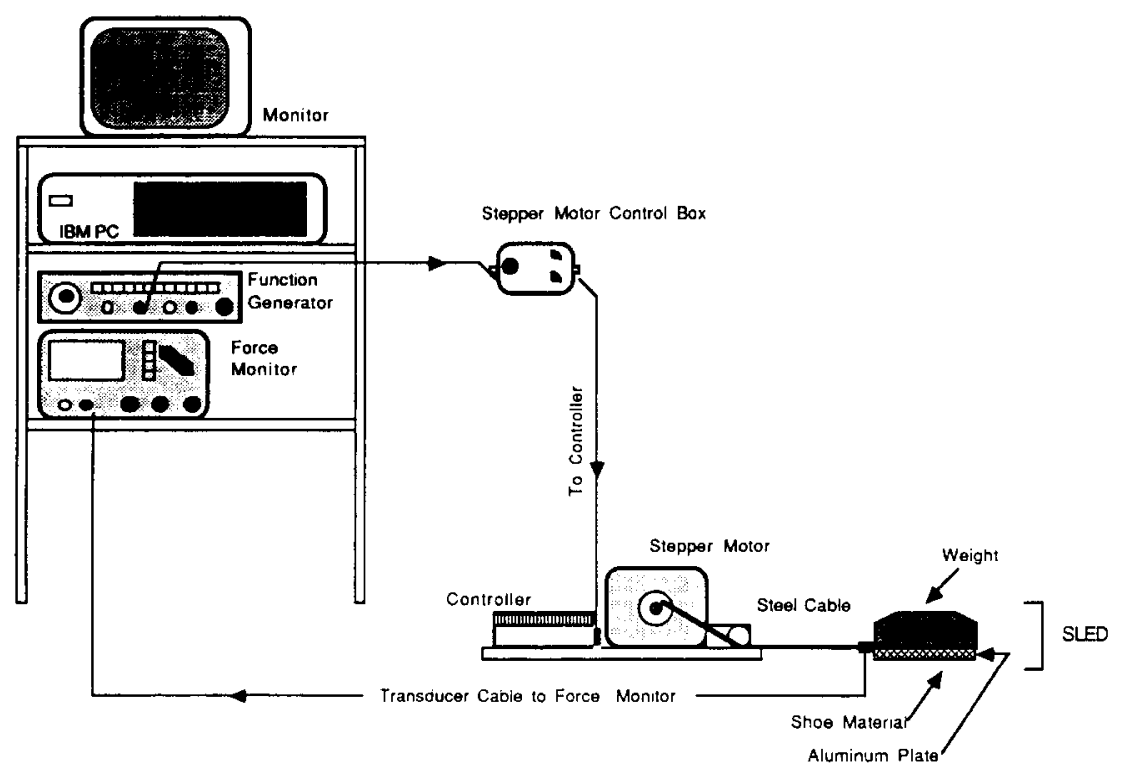


tion. Actual operation of the motor is controlled by the stepper motor controller, which consists of two switches and a "stop" button. The "on/off" switch controls the actual operation of the motor, while the "direction" switch controls the direction of the spindle rotation. The "stop" button interrupts regulation of the motor by the controller and can be used to stop rotation of the spindle during operation. The force measurement system includes a force transducer, force monitor, and data acquisition system. The force transducer (a custom strain-gauge beam-load cell) measures the amount of horizontal force required to pull the sled. The force monitor acts as a straingauge bridge amplifier to amplify the voltages coming from the load cell into voltages required by the $A / D$ converter.

Lab Tech Notebook (Laboratory Technologies Corp, 3.0.1 Megabyte version) data acquisition package was used with an IBM personal computer and monitor to run the trials and record the data. The system was calibrated to convert voltage from the load cell into $\mathrm{kg}$ of force by suspending known weights from the load cell over the estimated range of leading. A linear regression was performed for the calibration with a correlation coefficient of 0.995 . The values were used in the computer analysis of the results. Lab Tech Notebook provided a real-time plot of the forces recorded during each trial.

\section{Testing Procedure}

The following is a protocol established for conducting COF tests with the apparatus:

(1) Set the levels of the test variables (velocity, vertical force).

(2) Prepare the shoe-sole material sample (as per Andres \& Chapin, 1985) and attach to the bottom of the sled with double-stick adhesive tape.

(3) Place the sled with the desired weight on the floor surface so that all the slack in the cable is removed.

(4) Activate the computer data-acquisition system.

(5) Initiate the test by starting the stepper motor.

(6) Terminate data collection at the end of the excursion in the cable and then stop the motor.

\section{Data Analysis}

The forces are recorded from the load cell
FIGURE 2. REPRESENTATIVE DIAGRAM OF A TYPICAL HORIZONTAL FORCE TRACE PATTERN DURING A DYNAMIC COF TEST

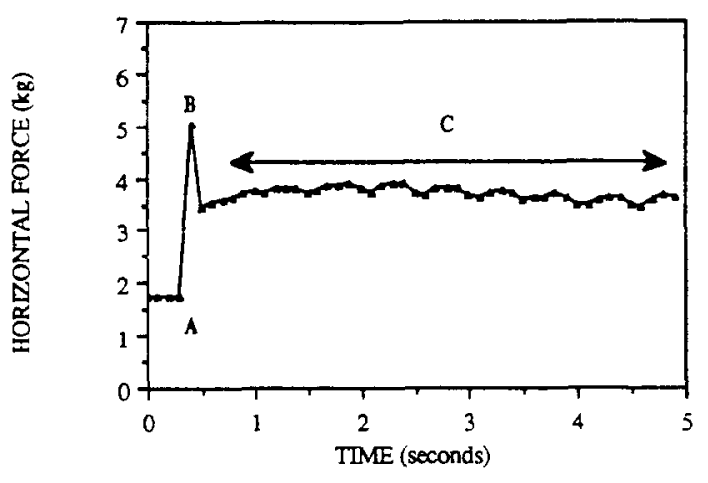

and the trial plotted on the screen. A typical trace recording appears in Figure 2. The horizontal or "pulling" force $(\mathrm{kg})$ required to sustain motion of the sled is plotted against the elapsed time(s) of the trial. The force trace does not start at zero because some tension was always maintained in the steel cable. Point "A" on the graph indicates where the stepper motor was activated. The trace immediately reaches its maximum at point " $B$," where the pulling force must overcome inertia and any adhesion effects at the shoe/floor interface. The trace rapidly falls and stabilizes as force is required only to sustain motion of the sled (range " $\mathrm{C}$ "). While the magnitude and stability of the traces differ between various test conditions, the same general pattern is present. A mean and standard deviation are calculated (over the "C" range) for each trial to assess the consistency of the data within a trial. A total of 10 trial repetitions are used for each condition. A grand mean and standard deviation are calculated for each condition using the 10 trial means to assess the consistency of the data between trials.

\section{Repeatability}

Data was collected using the device to investigate the repeatability of the dynamic COF measurements. A leather shoe sole was used on the vinyl floor tile with a dry, wet, and oily contaminant. Ten trials were performed at each condition under the prescribed testing protocol. Velocitics of $1,2,5$, and $10 \mathrm{~cm} / \mathrm{s}$ were tested with 
FIGURE 3. GRAPHIC PRESENTATION OF THE MEAN COF VALUES (X) IN THE REPEATABILITY STUDY
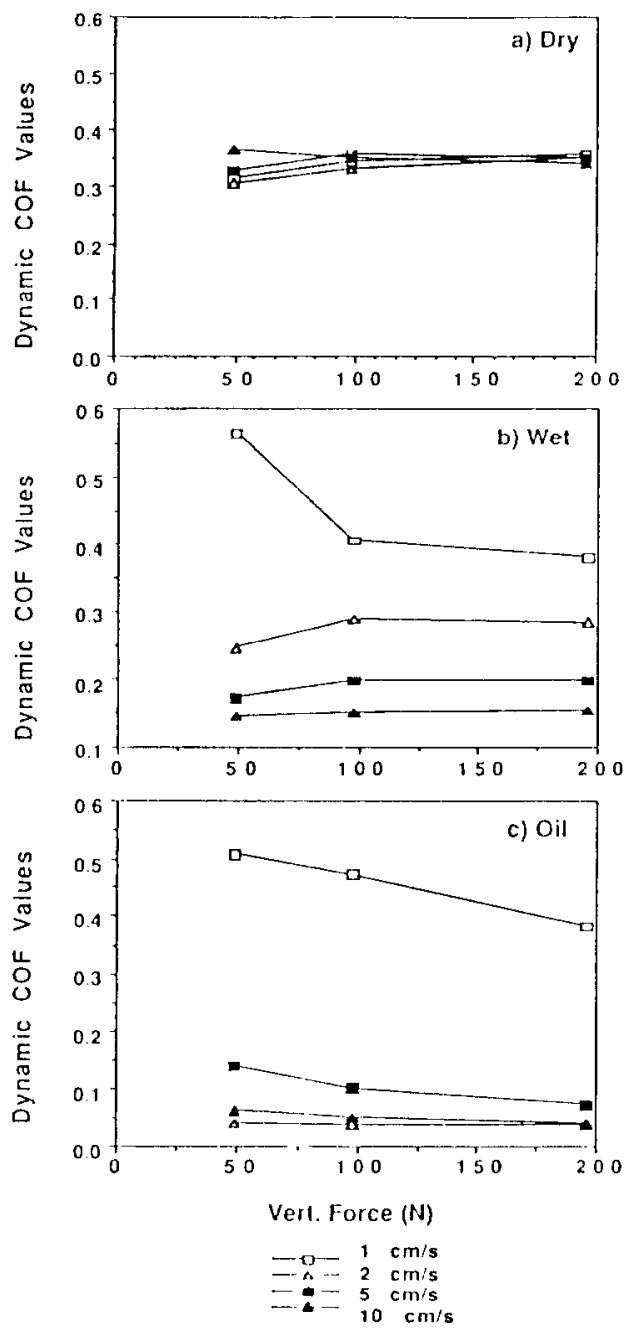

vertical forces of 49,98, and $196 \mathrm{~N}$ (equivalent to 5,20 , and $20 \mathrm{~kg}$ ). A full factorial design was implemented, requiring a total of 360 trials. A summary of the acquired dynamic COFs appears below (Table 1). Presented in the table are the means within each condition over the 10 trials $(X)$, the standard deviations of those means $\left(\mathrm{SD}_{\mathrm{X}}\right)$, and the means of the standard deviations found within each of the 10 trials $\left(\mathrm{X}_{\mathrm{sd}}\right)$. The $\mathrm{X}_{\mathrm{sd}}$ values were calculated by averaging the standard deviations found when computing the means of each trial (the data used in region "C"'[Figure 2]). The $X_{\text {sd }}$ 's demonstrated the stability of the recorded force data during the tests. The recorded force levels were very consistent with the $\mathrm{X}_{\mathrm{sd}}$ values being only $0.5 \%$ to $4 \%$ of the mean COFs (X). The $\mathrm{SD}_{\mathrm{X}}$ 's were also very low, with values $<3 \%$ of the mean. The $\mathrm{SD}_{\mathrm{x}}$ values were also consistent under all conditions tested.

A statistical analysis (ANOVA) of the data showed all primary independent variables (condition, speed, vertical force) to be significant $(p<.01)$ as were all first-order interactions. A comparison of Xs appears below (Figure 3). Velocity had very little effect on the dry surface, but had a great effect on the wet and oily surfaces. When the surface was wet, COFs decreased consistently as the velocity increased. However, when the surface was oily, the COFs dropped dramatically from the $1 \mathrm{~cm} / \mathrm{s}$ to the $2 \mathrm{~cm} / \mathrm{s}$ trials, then stayed at these lower levels as the speed was increased. Vertical force also had more of an effect under the wet and oily surface conditions, particularly at the slower velocities. The force effect appeared to decrease as the velocity increased.

\section{DISCUSSION AND CONCLUSIONS}

The dynamic COF measurement device described here can be used at different velocities of pull and at different vertical force levels. The device is easily implemented and offers flexibility for testing different shoe/floor condition combinations. The COF measurements acquired were shown to be highly repeatable from trial to trial under various velocities, vertical forces, and contaminant conditions. The COF results found in this study are consistent with some of the reported measurements in the literature. Andres \& Chaffin (1985) tested floors with a constant velocity COF device known as the TORTUS at $2 \mathrm{~cm} / \mathrm{s}$ with similar results. Because the effect of velocity during contaminated conditions reported here is very important to the practical testing of the floor/shoe interface, a variety of velocities needs to be tested to get a profile of the shoe/floor COFs to determine slip potential. Yet, it is believed that this device can be used in chosing and designing flooring 
TABLE 1. NUMERIC VALUES AND STANDARD DEVIATIONS

OF THE MEANS WITHIN 10 TRIALS

\begin{tabular}{|c|c|c|c|c|c|}
\hline Condition & $\begin{array}{l}\text { Velocity } \\
(\mathrm{cm} / \mathrm{s})\end{array}$ & $\begin{array}{l}\text { Vertical } \\
\text { Force (N) }\end{array}$ & $x$ & SDE & $\mathrm{X}_{\text {gd }}$ \\
\hline Dry & 1 & 49 & .314 & .004 & .013 \\
\hline Dry & 1 & 98 & .345 & .009 & .009 \\
\hline Dry & 1 & 196 & .356 & .006 & .007 \\
\hline Dry & 2 & 49 & .306 & .003 & .009 \\
\hline Dry & 2 & 98 & .329 & .006 & .008 \\
\hline Dry & 2 & 196 & .351 & .008 & .009 \\
\hline Dry & 5 & 49 & .32 .7 & .008 & .016 \\
\hline Dry & 5 & 98 & .356 & .009 & .013 \\
\hline Dry & 5 & 196 & .353 & .009 & .010 \\
\hline Dry & 10 & 49 & .363 & .008 & .013 \\
\hline Dry & 10 & 98 & .353 & .008 & .018 \\
\hline Dry & 10 & 196 & .342 & .007 & .010 \\
\hline Wet & 1 & 49 & .564 & .067 & .018 \\
\hline Wet & 1 & 98 & .406 & .046 & .009 \\
\hline Wet & 1 & 196 & .379 & .039 & .008 \\
\hline Wet & 2 & 49 & .246 & .020 & .017 \\
\hline Wet & 2 & 98 & .288 & .031 & .013 \\
\hline Wet & 2 & 196 & .285 & .035 & .009 \\
\hline Wet & 5 & 49 & .172 & .011 & .025 \\
\hline Wet & 5 & 98 & .198 & .018 & .026 \\
\hline Wet & 5 & 196 & .198 & .012 & .010 \\
\hline Wet & 10 & 49 & .147 & .008 & .024 \\
\hline Wet & 10 & 98 & .153 & .013 & .019 \\
\hline Wet & 10 & 196 & .154 & .012 & .002 \\
\hline $0 \mathrm{il}$ & 1 & 49 & .505 & .026 & .044 \\
\hline Oil & 1 & 98 & .472 & .070 & .025 \\
\hline Oi 1 & 1 & 196 & .381 & .077 & .013 \\
\hline oil & 2 & 49 & .042 & .018 & .009 \\
\hline Oil & 2 & 98 & .039 & .017 & .006 \\
\hline Oil & 2 & 196 & .039 & .011 & .004 \\
\hline Oil & 5 & 49 & .140 & .013 & .025 \\
\hline Oil & 5 & 98 & .100 & .018 & .011 \\
\hline Oil & 5 & 196 & .073 & .016 & .009 \\
\hline Oil & 10 & 49 & .063 & .011 & .017 \\
\hline Oil & 10 & 98 & .050 & .010 & .013 \\
\hline Oi 1 & 10 & 196 & .042 & .006 & .015 \\
\hline
\end{tabular}

systems for various settings under a variety of conditions to reduce slip-and-fall injuries.

\section{REFERENCES}

Andres, R. O., \& Chaffin, D. .B. (1985). Ergonomic analysis of slip-resistance measurement devices. Ergonomics, 28, 10651079.

Ellis, J. N. (1985). Protection systems curb deaths from falls. National Safety News, 131 (2), 40-43.

James, D. I. (1983), Rubbers and plastics in shoes and flooring:

The importance of kinetic friction. Ergonomics, 26, 73-82.

Manning, D. P., \& Shannon, H. S. (1981). Slipping

Summer 1990/Volume 21/Number 2 accidents causing low back pain in a gear box factory. Spine 6, 70-72.

Pater, R. (1985). How to reduce falling injuries. National Safety and Health News, 132, 87-91.

Perkins, P. J., \& Wilson, M. P. (1983). Slip resistance testing of shoesnew developments. Ergonomics, 26, 83-99.

Redfern, M. S., \& Adams, P.S. (1988). The effect of vertical force on static coefficients of friction. Proceedings of the Human Factors Society of Canada.

Redfern, M. S., \& Bloswick, D. (1987). Controlling slips and falls in industry. Occupational Health and Safety Magazine, 56, 34-43.

Strandberg, L. (1983). On accident analysis and slipresistance measurement. Ergonomics, 26, 11-32. 